THE KURUME MEDICAL JOURNAL Vol. 9, No. 2, 1962

\title{
CIRCULATORY RESPONSES TO ENDO-TRACHEAL INTUBATION. THE EFFECT OF CARBOCAIN - T SPRAY
}

\author{
TAKESUKE MUTEKI, YASUHIRO NAKAMURA, \\ IKURO IMAZATO, HUMIHIDE SUENAGA, \\ YOSHIHIRO NAKAMURA, HISAO YOKOYAMA, \\ AND HISATOSHI IKUTA
}

Department of Anesthesiology, Kurume University School of Medicine, Kurume, Japan

Induction of anesthesia always is the most important problem for the anesthetist, because during this period the patent is susceptible to dangers and complications.

Furthermore, the cardiovascular state during this period is so unstable that any stimulation, either due to anesthetic or surgical procedures, inadequately added, will deteriorate it; the tracheal intubation or even insertion of the laryngescope into the mouth, will of ten cause remarkable circulatary responses during this period.

The responses, notably the pressor response, could be followed by a mishap particularly in the aged or hypertensive patients, and poor risk patients with cardiovascular dysfunction.

Although the circulatory responses to tracheal intubation have been observed by many investigators and variously interpreted ${ }^{132(3) 4) 5}$, almost no report is available on the problem of prevention or inhibition of the responses ${ }^{6}$.

Therefore, we have used five percent solution of Carbocain in an attempt to anesthetize the laryngeal, and the pharyngeal areas and the base of the tongue with spray prior to tracheal intubation and discussed its inhibitory effect on the pressor reflex mechanism mediated over the sympatheticus which is innervated in these areas.

\section{METHODS}

1) The circulatory responses to tracheal intubation hav been observed in fifty adult patients including the heart-diseased or hypertensive, and the aged, (over 60 years of age), by measuring the blood pressure during tracheal intubation.

2) The five percent carbocain contained in a push-button spray bottle was used at least five sprays were applied about five minutes prior to induction of anesthesia in order to obtain a satisfactory anesthesia of the laryngeal and the pharyngeal surfaces and the base of the tongue in an attempt to inhibit the pressor reflex mechanism during tracheal intubation.

3) In order to investigate its inhibitory effect, the blood pressure changes obtained during tracheal intubation in the Carbocain-sprayed group, 23 cases, were com- 
TABLE 1

Blood Pressere Change During Intubation of the Control Group

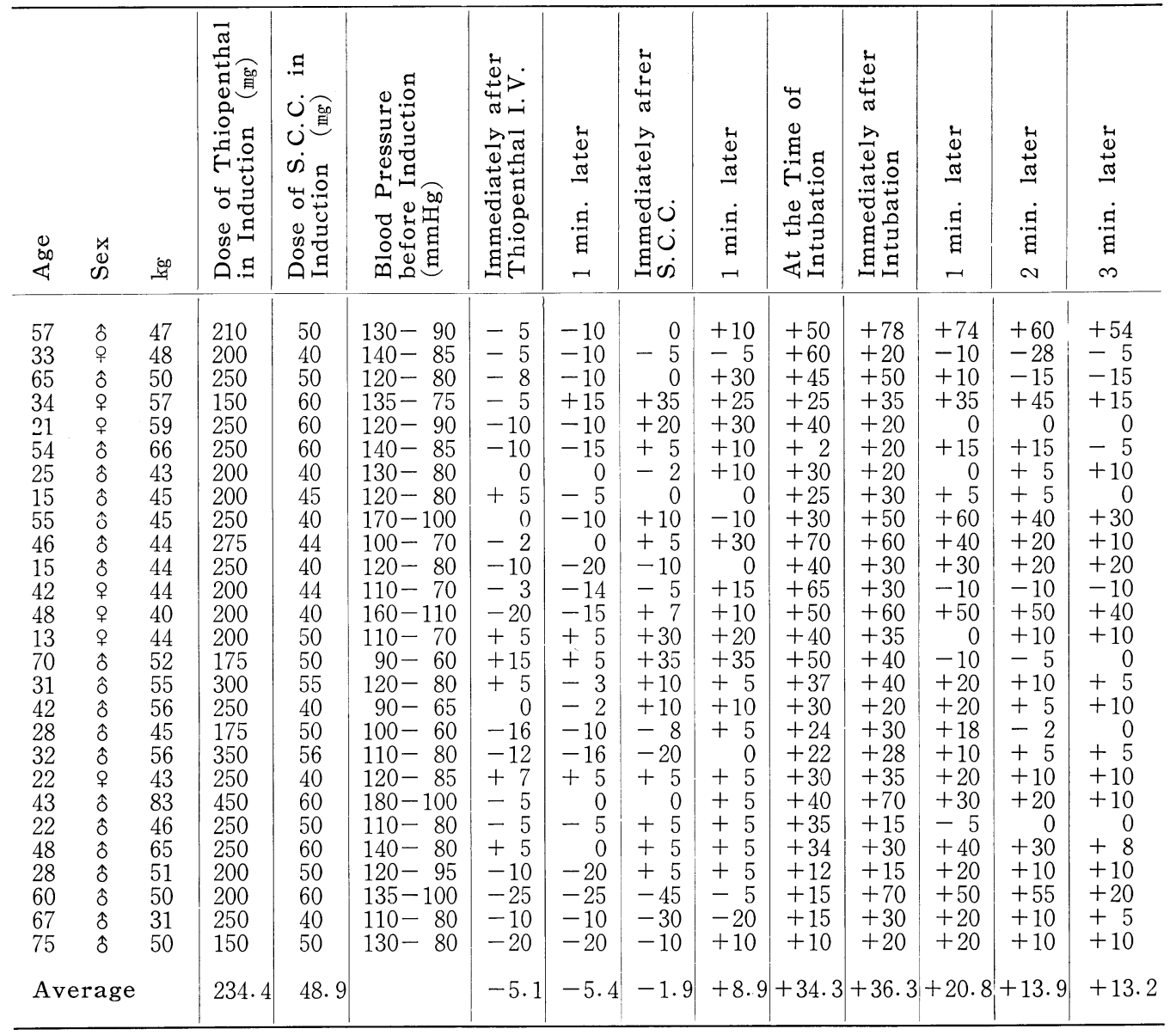

pared with those in the control group, 27 cases.

4) Induction of anesthesia was performed with a slow intravenous injection of Thiopenthal (2.5 percent Isozol). Its initial dose was determined by administering directly into the vein at the rate of $5 \mathrm{mg}$ per second until loss of consciousness had been obtained. Half of the initial dose was added later.

5) Tracheal intubation was routinely made by Macintosh's laryngoscope until good muscle relaxation was obtained by succinylcholine chloride $1 \mathrm{mg} / \mathrm{kg} \mathrm{I}$. V. and good oxygenation was produced by ventilating with 100 percent oxygen under a well-fitting mask for several minutes.

6) Blood pressure was taken by Riva-Rocci's sphygnomanometer with the cuff applied to the left upper arm. It was taken as a control value at the time of arrival at the operating theater and again approximately 45 minutes later, after the regimen-involved Demerol $1 \mathrm{mg} / \mathrm{kg}$ and atropine $0.1 \mathrm{mg} / 10 \mathrm{~kg}$ were given intramuscularly. It was then taken immediately after and one minute after the 
TABLE 2

Blood Pressure Change During Intubation of the Carbocain-sprayed Group

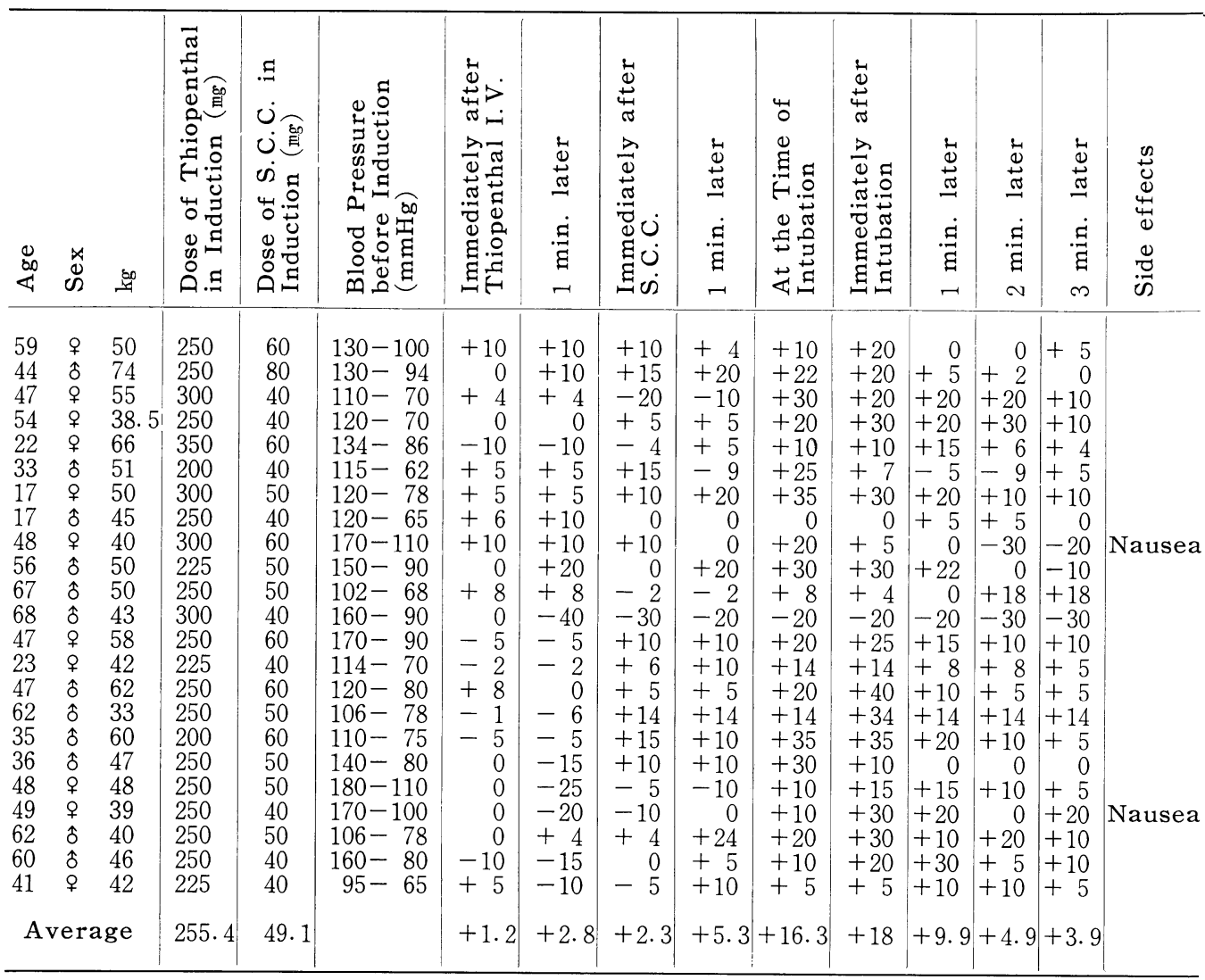

respective administrations of thiopenthal and succinyl choline chloride and at the time of endo-tracheal intubation and then one, two and three minutes after intubation.

\section{RESULTS}

1. The fifty patients, 13 to 75 years old, almost all showed the pressor response to the tracheal intubation as shown in Table 1 and Table 2.

2. In the Carbocain-sprayed group, 23 cases, the rise of blood pressure during tracheal intubation was significantly diminished with the range of the values zero to $35 \mathrm{mmHg}$, averaging $16.3 \mathrm{mmHg}$. In the control group, $27 \mathrm{case}$, at the moment of tracheal intubation the blood pressure rose with the values ranging from 2 to $70 \mathrm{mmHg}$, averaging $34.3 \mathrm{mmHg}$.

3. The aged patients, over 60 years of age, were particularly investigated in respect to circulatory responses to the tracheal intubation. All the patients had a favourably marked rise of blood pressure during intubation except one hypertensive patient who showed a slight fall of blood pressure. Carbocain was used for 
Fig. 1. Blood Pressure Change During Tracheal Intubation.

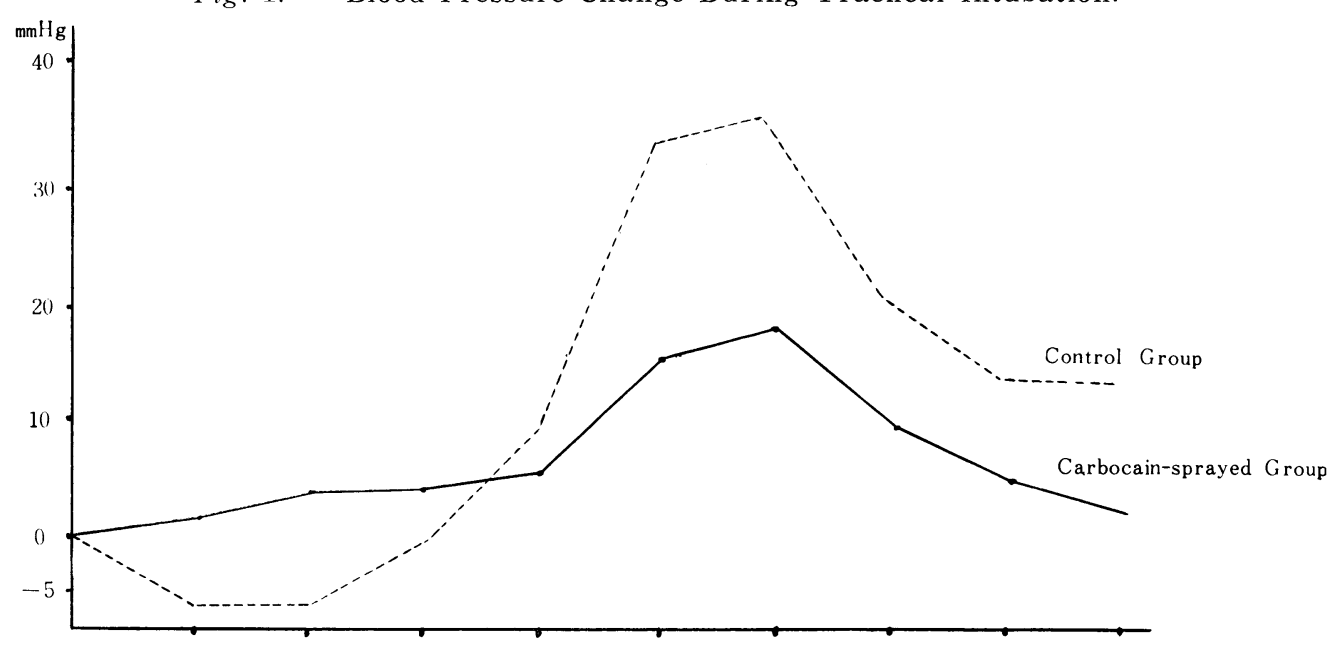

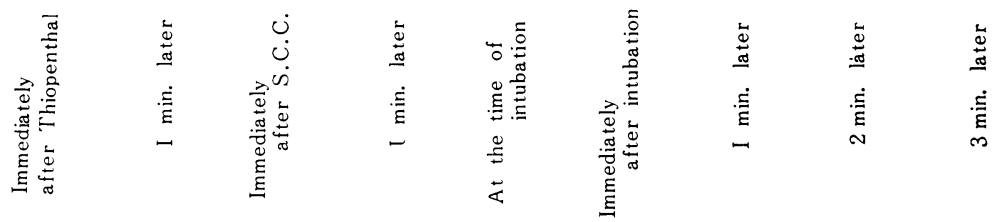

TABLE 3

Blood Pressure Change During Intubation of the Aged Patients

\begin{tabular}{|c|c|c|c|c|c|c|c|c|c|c|c|c|c|c|}
\hline$\underset{\infty}{\infty}$ & $\stackrel{x}{\Delta}$ & 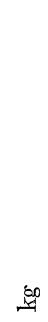 & 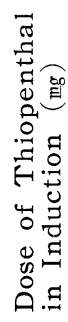 & 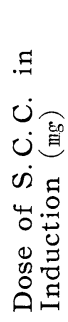 & 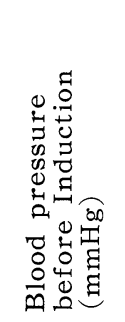 & 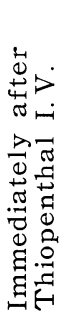 & 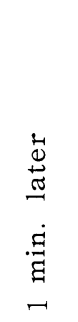 & 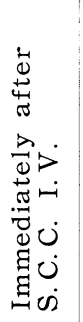 & 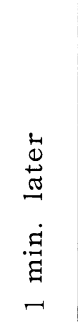 & 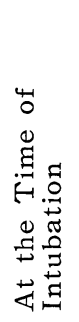 & 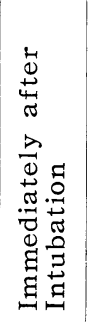 & $\begin{array}{l}\stackrel{\Delta}{ \pm} \\
\stackrel{\Delta}{\Xi} \\
\dot{\Xi} \\
\stackrel{\Xi}{\Xi} \\
-1\end{array}$ & 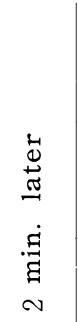 & 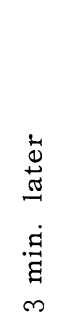 \\
\hline & & 10 & \multicolumn{12}{|c|}{ Carbocain-sprayed Group } \\
\hline $\begin{array}{l}67 \\
68 \\
62 \\
62 \\
60\end{array}$ & $\begin{array}{l}\hat{0} \\
\hat{0} \\
\hat{0} \\
\hat{0} \\
\hat{0}\end{array}$ & $\begin{array}{l}50 \\
43 \\
33 \\
40 \\
42\end{array}$ & $\begin{array}{l}250 \\
300 \\
250 \\
250 \\
225\end{array}$ & $\begin{array}{l}50 \\
40 \\
50 \\
50 \\
40\end{array}$ & $\begin{array}{r}102-68 \\
160-90 \\
106-78 \\
106-78 \\
95-65\end{array}$ & $\begin{array}{r}+8 \\
0 \\
-\quad 1 \\
0 \\
+\quad 5\end{array}$ & $\begin{array}{l}+8 \\
-40 \\
-6 \\
+4 \\
-10\end{array}$ & $\begin{array}{l}-2 \\
-30 \\
+14 \\
+4 \\
-5\end{array}$ & $\begin{array}{l}-2 \\
-20 \\
+14 \\
+24 \\
+10\end{array}$ & $\begin{array}{l}+8 \\
-20 \\
+14 \\
+20 \\
+5\end{array}$ & $\begin{array}{l}+4 \\
-20 \\
+34 \\
+30 \\
+5\end{array}$ & $\begin{array}{r}0 \\
-20 \\
+14 \\
+10 \\
+10\end{array}$ & $\begin{array}{l}+18 \\
-30 \\
+14 \\
+20 \\
+10\end{array}$ & $\begin{array}{l}+18 \\
-30 \\
+14 \\
+10 \\
+5\end{array}$ \\
\hline \multicolumn{3}{|c|}{ Average } & 255 & 46 & & +2.4 & -8.8 & -3.8 & +5.2 & +5.4 & +10.6 & +2.8 & +6.4 & +3.4 \\
\hline
\end{tabular}

\section{Control Group}

\begin{tabular}{|c|c|c|c|c|c|c|c|c|c|c|c|c|c|c|}
\hline 65 & $\hat{\jmath}$ & 50 & 250 & 50 & $120-80$ & -8 & -10 & 0 & +30 & +45 & +50 & +10 & -15 & -15 \\
\hline 70 & $\hat{0}$ & 52 & 175 & 50 & $90-60$ & +15 & +5 & +35 & +35 & +50 & +40 & -10 & -5 & 0 \\
\hline 60 & $\hat{\delta}$ & 50 & 200 & 60 & $135-100$ & -25 & -25 & -45 & -5 & +15 & +70 & +50 & +55 & +20 \\
\hline 67 & $\hat{0}$ & 31 & 250 & 40 & $110-80$ & -10 & -20 & -30 & -20 & +15 & +30 & +20 & +10 & +5 \\
\hline 75 & $\hat{0}$ & 50 & 150 & 50 & $130-80$ & -20 & -10 & -10 & +10 & +10 & +20 & +20 & +10 & +10 \\
\hline \multicolumn{3}{|c|}{ Average } & 205 & 50 & & -9.8 & -12 & -10 & +10 & +25 & +40.2 & +18 & +11 & +4 \\
\hline
\end{tabular}




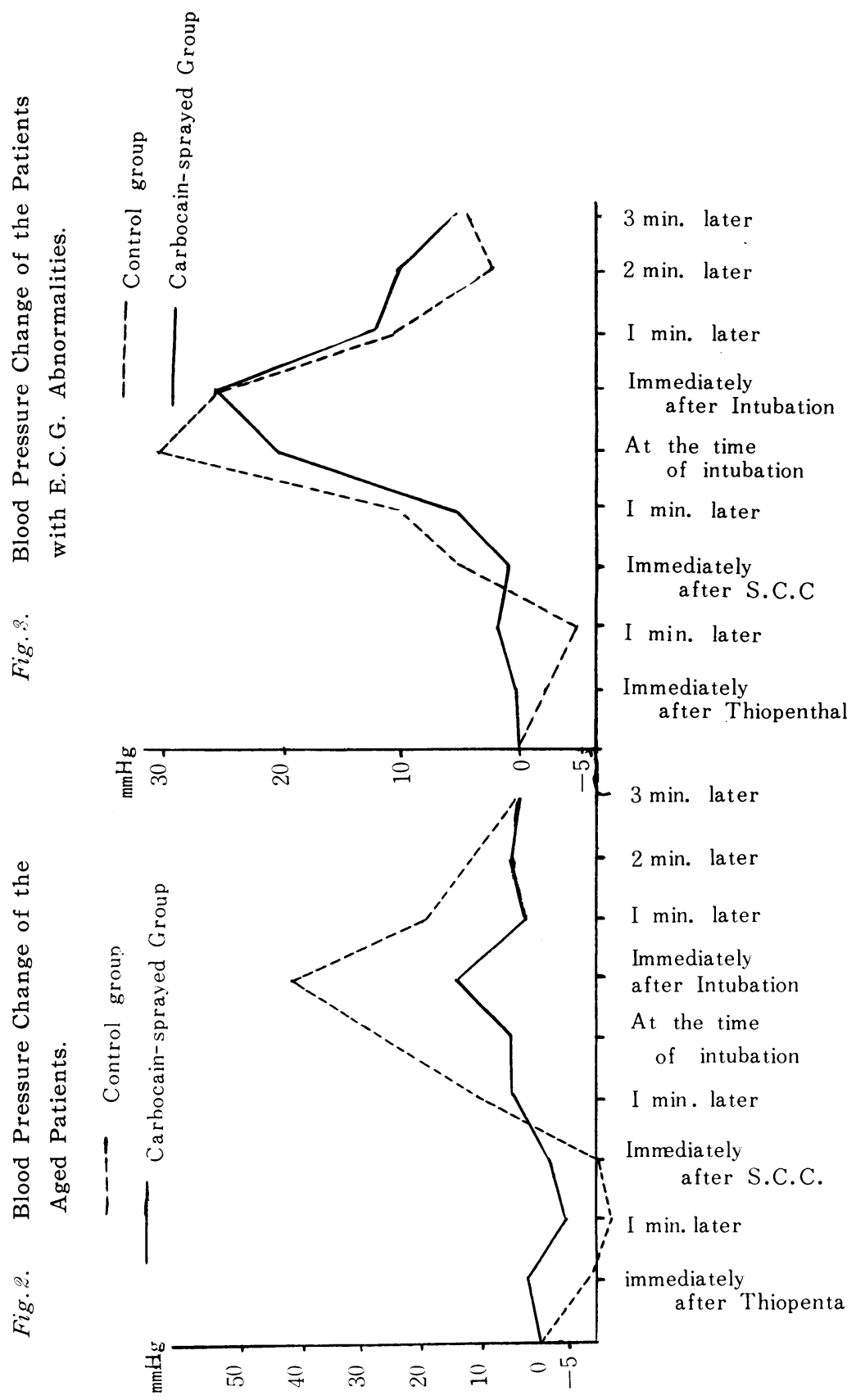

the five cases in this group and it was noted that in the control group the blood pressure had markedly risen as much as 5 to 8 times higher than in the Carbocainsprayed group. (Table 3, Fig. 2) 
TABLE 4

Blood pressure Change of the Patients wtih E.C.G. Abnormalities

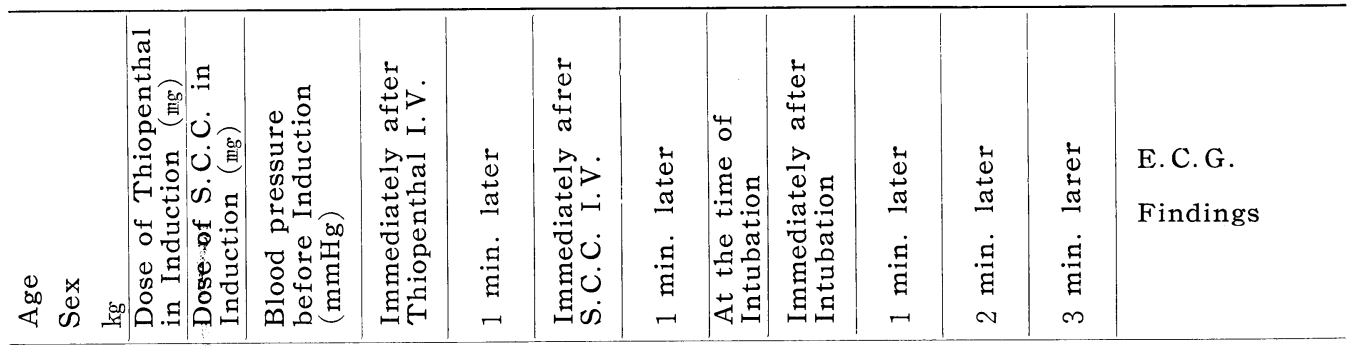

1. Carbocain-sprayed Group

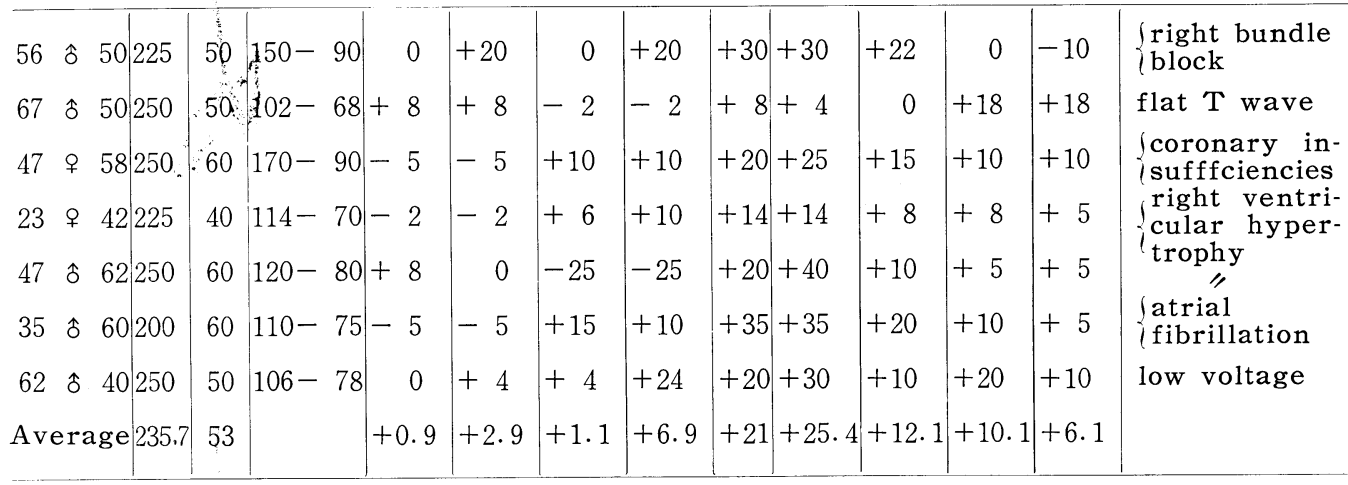

\section{Control Group}

\begin{tabular}{|c|c|c|c|c|c|c|c|c|c|c|c|c|c|c|}
\hline 21 & q & \begin{tabular}{l|l}
59 & 250
\end{tabular} & 60 & $120-90$ & -10 & -10 & +20 & +30 & +40 & +20 & 0 & 0 & 0 & $\left\{\begin{array}{l}\text { lowered S-T } \\
\text { segment }\end{array}\right.$ \\
\hline 25 & $\hat{o}$ & 43200 & 40 & $130-80$ & 0 & 0 & -2 & +10 & +30 & +20 & 0 & +5 & +10 & " \\
\hline 70 & 우 & 52175 & 50 & $90-60$ & +15 & +5 & +35 & +35 & +50 & +40 & -10 & -5 & 0 & " \\
\hline 31 & $\hat{o}$ & 55300 & 55 & $120-80$ & +5 & -3 & +10 & +5 & +37 & +40 & +20 & +10 & +5 & $\left\{\begin{array}{l}\text { atrial } \\
\text { fibrillation }\end{array}\right.$ \\
\hline 42 & $\hat{o}$ & 56250 & 40 & $90-65$ & 0 & -2 & +10 & +10 & +30 & +20 & +20 & +5 & +10 & " \\
\hline 28 & $\hat{\delta}$ & 45175 & 50 & $100-60$ & -16 & -10 & -8 & +5 & +24 & +30 & +18 & -2 & 0 & Mitral-P \\
\hline 32 & $\hat{o}$ & 56350 & 56 & $110-80$ & -12 & -16 & -20 & 0 & +22 & +28 & +10 & +5 & +5 & $\left\{\begin{array}{l}\text { atrial } \\
\text { fibrillation }\end{array}\right.$ \\
\hline 22 & q & 43250 & 40 & $120-85$ & $5+7$ & +5 & +5 & +5 & +30 & +35 & +20 & +10 & +10 & $"$ \\
\hline 22 & $\hat{\delta}$ & 46250 & 50 & $110-80$ & -5 & -5 & +5 & +5 & +35 & +15 & -5 & 0 & 0 & " \\
\hline 28 & $\hat{o}$ & 51200 & 50 & $120-95$ & -10 & -20 & +5 & +5 & +12 & +15 & +20 & +10 & +10 & extrasystoles \\
\hline & & 240 & 49.1 & & -2.6 & -5.6 & +6 & +11 & +31 & +26.3 & +6.3 & +3.8 & +5.0 & \\
\hline
\end{tabular}

4. The same investigation was conducted on 17 patients who preoperatively had the abnormalities of electrocardiogramm, such as right bundle block, supraventricular premature beats, flat or inverted $\mathrm{T}$ wave, lowered $\mathrm{S}-\mathrm{T}$ segment, and mitral P. etc.

The rise of blood pressure markedly diminished in the seven patients in this 
group who had the Carbocain sprayed prior to induction while it was increased in the control group.

5. None of the untoward reactions related to the carbocain spray were noted except for two patients who become nauseated immediately after it was sprayed.

\section{DISCUSSION AND CONCLUSION}

The circulatory responses to tracheal intubation under thiopenthal general anesthesia have been observed in order to investigate whether the circulatory responses would be inhibited by anesthetizing the pharyngeal and laryngeal area and the base of the tongue with a topical spraying of five percent Carbocain.

Although the mechanism of the circulatory responses to tracheal intubation has been variously interpreted, it is generally recognized that the reflex mechanism mediated over the sympatheticus at the base of the tongue would cause a pressor response due to the mechanical stimulation to the base of the tongue with a tip of the laryngoscope during tracheal intubation ${ }^{5}$.

The circulatory reflex due to tracheal intubation frequently exhibited a pressor response and may be less significant to an ordinary patient under the satisfactory level of general anesthesia, for the responses are usually transient and easily restored without any untoward reaction $s^{6)}$ ).

However, for the aged, hypertensive or poor-risk patients, especially those with cardiovascular diseases, circulatory reponses to tracheal intubation will deteriorate the cardiovascular status of the patient and the danger of cerebral vascular damage or cardiac failure would be frequently anticipated ${ }^{4 / 6}$.

Accordingly, the attempt to prevent or inhibit the circulatory response due to tracheal intubation; notably, the rise of blood pressure is extremely significant to such patients.

We have noted that the pressor responses to tracheal intubation were satisfactorily inhibited by spraying five percent Carbocain to the pharyngeal area prior to induction. This result indicates that the pressor reflex mechanism mediated over the sympatheticus, and that the vagus has been blocked by spraying the carbocain at the pharyngeal, and the laryngeal areas and at the base of the tongue.

Five per cent Carbocain possesses as much potent and excellent action as an adequate topical anesthesia which has been obtained within a few minutes without any particular side-effects.

In conclusion, the maneuver to spray the mouth with five per cent Carbocain in order to obtain an anesthesia of the pharyngeal, and the laryngeal surfaces and the base of the tongue would be recommended in order to prevent the circulatory responses which may be followed by sericus cardiovascular complications, especially in the case of the aged, hypertensive, and poor-risk patients. 


\section{REFERENCES}

1. YUtAKa ONChI: The Use of Carbocain Spray. The Japanese Journal of Anesthesio$\log \mathrm{y}, 11,182,1962$.

2. Koлr Takeshima: The Changes in Cardiovascular System during Endotracheal Intubation, The Japanese Journal of Anesthesiology, 11, 402, 1962.

3. Wycoff, C.C. : Endotracheal intubation: Effects on Blood Pressure and Pulse rate. Anesthesiology, 21, 153, 1960.

4. King, B. D., Harris, L. C., Tr., Greifenstein, F. E., Elder, T. D. , Tr, and Dripps, R. D. : Reflex Circulatory Responses to Direct Laryngoscopy and Tracheal Intubation Performed during General Anesthesia. Anesthesiology, 12, 556, 1951.

5. Masayoshi Hyodo: Changes in Cardiovascular Function Caused by Laryngoscopy and Endotracheal Intubation, The Japanese Journal of Anesthesiology, 8, 720, 1959.

6. Aкira Inaмото: Endotracheal Intubation and Cautions, The Japanese Journal of Anesthesiology. 9, 683, 1960.

7. John. J. Downes, M. D., Joseph F. Wilscn., M. D., David Goodson, M. D. : Apnea, Suction and Hyperventilation Effect on Arterial Oxygen Saturation. Anesthesiology, 22, 29, 1961. 